ON THE HABITS AND THE POSE OF THE SAUROPODOUS DINOSAURS, ESPECIALLY OF DIPLODOCUS

\author{
DR. OLIVER P. HAY
}

Washington D. C.

To most persons the habits of living animals are more interesting than is their anatomy. The same is probably even more true with respect to the extinct animals. However, when it comes to determining the habits of extinct animals, their aquatic or terrestrial habitat, their modes of progression, their bearing on their limbs, their food and their ways of procuring it, their modes of attack and defense against their enemies, their manner of reproduction, etc., we meet with many difficulties.

The Sauropoda, and especially the species of Diplodocus, offer a fine illustration of the difficulties mentioned. Were they aquatic, or terrestrial, or amphibious? Did they affect dry lands, or swamps, or rivers and lakes? Did they eat vegetable food or did they prey on other animals? Did they chew their food or did they bolt it? Did they bring forth living young or did they lay immense eggs? Did they make bold attacks on their enemies or were they timid and cowardly creatures? Did they walk only, or swim only, or did they employ both methods of transporting their huge bodies? If they walked, was it on all four legs or on the hinder ones only? If on all four, did they carry their bodies high above the ground, after the manner of the ox and the horse, or did they carry them low down, like the crocodiles, perhaps dragging their bellies on the ground?

To some of these questions more or less definite answers have been made and accepted; others remain unanswered. It is pretty well agreed that a part of their time was passed in the water; that they could swim 
readily; that they walked mostly on all fours; that to some extent at least they went about on land; that their food was mainly, if not wholly, vegetable; and that they had imperfect or no means of chewing it.

We are assisted in understanding the habits of these creatures by a knowledge of the nature of their environment. And this we must determine from the character of the deposits in which their bones are discovered and from the kinds of animals and plants accompanying them. Investigation has shown that their remains occur in sandstones and clays which were certainly laid down in fresh waters having no great amount of motion. The accompanying animals are other dinosaurs, some herbivorous, others carnivorous; besides crocodiles, turtles, freshwater fishes and freshwater shells. Some of the plants that occur in the deposits certainly lived in fresh water.

Hatcher $^{1}$ has discussed at length the nature of the region in which the species of Diplodocus and their allies lived, as well as the habits of the Sauropoda in general; and the present writer agrees with him on most points. Hatcher believed that the Atlantosaurus beds were deposited, not in an immense freshwater lake, as held by some geologists, but over a comparatively low and level plane, which was occupied by perhaps small lakes connected by an interlacing system of river channels. The climate was warm and the region was overspread by luxuriant forests and broad savannas. The area thus occupied included large parts of the present states of Colorado, New Mexico, Utah, Montana, and the Dakotas. In his memoir on Diplodocus, Hatcher ${ }^{2}$ compares the conditions prevailing in that region during the Upper Jurassic to those now found about the mouth of the Amazon and over some of the more elevated plains of western Brazil. In such regions the rivers, fed from distant elevated lands, must have been subject to frequent inundations.

${ }^{1}$ Mem. Carnegie Mus., II, 1903, pp. 54-67.

${ }^{2}$ Mem. Carnegie Mus., I, p. 60. 
The beds of the streams were continually shifting, and there existed numerous abandoned channels that were filled with stagnant water. An animal that lived in such a region would be compelled to adapt itself to a more or less aquatic life, and this adaptation would be reflected to a greater or less extent in the structure of the animal. Marsh had concluded from the position of the external nares of Diplodocus that it was addicted in some measure to an aquatic existence. The feet too are of rather peculiar structure, the inner toes being strongly clawed, the outer toes greatly reduced; but the meaning of this is differently interpreted.

\section{The Food of Diplodocus}

The particular sort of food eaten by the species of Diplodocus is unknown, but nobody doubts that it was vegetable. The teeth were pencil-like in form and they were entirely confined to the front of the jaws. By general consent, they could have been employed only for prehension of food, not at all for its mastication. Hatcher suggested that the teeth might have been useful in detaching from the bottoms and shores the tender and succulent aquatic and semi-aquatic plants that must have grown there in abundance. Osborn" says that "the food probably consisted of some very large and nutritious species of water plant. The anterior claws may have been used in uprooting such plants. . . . The plants may have been drawn down the throat in large quantities without mastication." In a restoration of Diplodocus by Mr. Charles W. Knight ${ }^{4}$ the animal is represented as standing on its hind legs and preparing to bite off the terminal bud of a towering cycad. Holland ${ }^{5}$ thinks that the teeth were better adapted for raking and tearing off from the rocks soft masses of clinging algæ than for securing any other forms of vegetable food now represented in the waters of the world.

${ }^{3}$ Mem. Amer. Mus. Nat. Hist., T, p. 214.

${ }^{4}$ Scientific American, XCVI, 1907, p. 485.

${ }^{5}$ Mem. Cannegie Mus., II, p. 240. 
To the present writer the suggestion of Dr. Holland has in it more of probability than any of the others presented. If the food-plants sought by Diplodocus had been large and such as required uprooting by the great claws of the reptile the prehension and manipulation of the masses would have been liable to break the slender teeth and would certainly have produced on them perceptible wear. The upper teeth of the original of Marsh's figures on Plate XXV of the Dinosaurs of North America ${ }^{6}$ show no wear, so far as the writer can determine. The mandibular teeth are not well exposed to view.

With respect to Osborn's theory, it is well to take into consideration also the probable ability of the reptile to digest great masses of undivided and unmasticated vegetation. Against the theory suggested by Knight's restoration it may be urged that the teeth, pointed or slightly chisel-shaped, are poorly adapted for cropping leaves and great buds; most of all, the teeth have spaces between them, like the teeth of a great comb, an arrangement not favorable to their functioning as cutting instruments. The teeth could hardly have been used for scraping algæ from rocks, either, for that usage would have produced evident and rapid wear. It is more probable that the food consisted of floating alga and of plants that were loosely attached to the bottoms of stagnant bayous and ponds. Hatcher has reported the finding of the seeds and the stems of a species of Chara near the Marsh quarry, where many Sauropoda have been found. This alga, it seems to the writer, would have been admirably adapted to the needs of Diplodocus. It could be easily gathered into the mouth as the reptile swam or crawled lazily about or rested itself and retracted and extended its long neck. The long and highly vaulted palate would have permitted a considerable mass to be collected, out of which, by pressure of the tongue, the superfluous water might have been squeezed between

${ }^{6}$ (Cat. No. 2672, U. S. Nat. Mus.)

${ }^{\top}$ Mem. Carnegie Mus., II, p. 63. 
the spaced teeth. In addition to various alga there were probably other floating plants.

\section{The Posture of Diplodocus}

Marsh presented no restoration of Diplodocus, but he did furnish restorations of Brontosaurus; and he stated that he regarded it as representing the general form and proportions of the Sauropoda. In this figure Brontosaurus is shown as walking with the body high above the ground and with the limbs, especially the hinder ones, about as straight as they are in the elephant.

So far as the bearing of Brontosaurus and Diplodocus on their limbs is concerned, Marsh's example has been almost slavishly followed ever since. No one, so far as the writer knows, has ventured to defend in print a more crocodilian posture. Osborn ${ }^{\mathrm{S}}$ grants that there is room for wide differences of opinion as regards the habits and means of locomotion of these gigantic animals and states that some hold the opinion that on land at least these reptiles had rather the attitude of the alligator. The same writer says in Nature, vol. 73, 1906, p. 283, that Dr. Matthew and Mr. Gidley have maintained the latter view. However, the trend of opinion seems to have been in the opposite direction. Osborn ${ }^{9}$ suggested that Diplodocus might lift its fore limbs from the ground and support itself on the hinder legs and the tail. This idea has found expression in Knight's restoration referred to above. Osborn's general notion of Diplodocus seems, however, to be that it was essentially an aquatic animal, long, light-limbed, and agile, and capable of swimming rapidly by means of its great tail, provided, as he thought, with a vertical fin; yet occasionally going about on land. Hatcher ${ }^{10}$ opposed the view that Diplodocus was aquatic; and he showed that there is no evidence of the presence of a vertical fin. The compression of the

\footnotetext{
science, XXIT, 1905, p. 376.

${ }^{9}$ Mem. Amer. Mus. Nat. Hist., T, p. 213.

${ }^{10}$ Mem. Carnegie Mus., II, 1903, p. 59.
} 
centra where the fin is supposed to have been situated seems to have been slight, and the neural spines are not higher than elsewhere. The present writer finds neither in the feet nor in the tail any special arrangements for swimming. For navigation in its restricted waters no fin was needed. Almost any colubrid snake makes fair progress in the water, notwithstanding the absence both of a compressed tail and of a vertical fin.

Hatcher's final view does not, after all, appear to have been greatly different from that of Osborn. He held that Diplodocus, as well as most of the Sauropoda, were essentially terrestrial animals, but that they passed much, perhaps most, of their time in shallow water, where they could wade about and search for food. He believed that they were ambulatory, but quite capable of swimming. Hatcher's language does not necessarily imply that these animals walked about after the fashion of quadrupedal mammals, but his restorations show plainly that such was his conception.

This conception has prevailed in the plaster reproductions of the skeleton of Diplodocus which have been sent abroad by the Carnegie Museum and set up in London, Berlin and Paris; and in the small plaster restorations issued by the American Museum of Natural History. However, the limit of quadrupedal erectness, rigidity, rectangularity, and rectilinearity has quite been reached in the skeleton sent by the last mentioned institution to the Senckenberg Museum, at Frankfort-on-the-Main. In this case the poor beast is made to stand straight-legged and almost on the tips of its digits. On the other hand, the American Museum's skeleton of Brontosaurus, a much larger and heavier reptile and one sorely needing the mechanical advantage of straight leg's, in case it had to bear its body free from the ground, has been presented to the modern world as having been decidedly bow-legged.

To the present writer it appears that the mammal-like pose attributed to the Sauropoda is one that is not required by their anatomy and one that is improbable. 
The current conception is one that is easily accounted for. Before exact knowledge of these reptiles had been gained, it was known that the dinosaurs of the other groups, herbivorous and carnivorous, walked erect, after the manner of birds. It was indeed necessary, on account of the length of the fore limbs, to place the Sauropoda on all four feet; but analogy caused it to be supposed that the limbs were disposed, with reference to the vertical plane of the body, similarly to those of the bipedal dinosaurs. The conception of a creeping dinosaur was hardly to be entertained. The straight femora of these reptiles, having the head and the great trochanter moderately developed, lent probability to the idea.

If the straightness of the femora is relied on to support the correctness of the prevailing restorations of the Sauropoda we may call attention to the equally straight femora of sphenodon and of the lizards. Notwithstanding the great size of the carnivorous dinosaur Allosaurus and the fact that the whole weight of its body was commonly borne by the hinder limbs alone, its femora are considerably bent. The prominence and the height of the great trochanter of the Sauropoda do not appear to be such as to have prevented the femora from standing out at right angles with the body. Both the head of the femur and the acetabulum were doubtless invested with much cartilage, so that we can not now be wholly certain about their form and fitting. The same may be said regarding certain other articulations of the limbs. Hatcher ${ }^{11}$ has spoken of the character of the articulations and he has expressed the opinion that the habitual support of the body in the air could not have failed to produce closely applied and well-finished articulations, and Osborn had previously expressed the same idea. ${ }^{12}$ There is indeed a great difference between the articulations of the limbs of the Sauropoda and those of the Theropoda, such as Allosaurus and Ceratosaurus.

${ }^{11}$ Mem. Carnegie Mus., I, p. 59.
${ }^{12}$ Bull. Amer. Mus Nat. Hist., X, p. 220. 
Osborn ${ }^{13}$ has found in the large preacetabular process an argument in favor of the ability of Diplodocus to elevate the anterior part of its body. However, Trachodon, which habitually walked on its hind legs has a very insignificent preacetabular process. The crocodiles have a strongly developed process in front of the acetabulum.

It appears to the writer that the structure of the feet of the Sauropoda indicates that the digits were directed somewhat outward, instead of directly forward, as they are placed in the restorations. The strongly developed inner digits would then have come more effectively into contact with the ground than the much reduced outer digits and would have been employed by the animal as a means of pushing itself along. In case the lower end of the radius is placed in front of the ulna, as represented by Hatcher ${ }^{14}$ it appears probable that the foot would be directed more strongly outward than is shown in his restoration..$^{15}$

The writer is not aware that any one has held that the Sauropoda could not, at least while resting, assume a crocodile-like posture, with the abdomen on the ground and the limbs extended outward on each side. If such a position is admitted as possible, the arguments derived from the anatomy in favor of an erect mode of walking are greatly weakened. If such a pose was not assumed, what was the pose? Did Diplodocus and Brontosaurus lie down on their sides, as an ox or a horse does when sleeping? Or did they lie prone, with the limbs drawn up under them, as a dog sometimes does? These positions appear to be improbable. It is worth considering too what disposition Diplodocus made of its elephantine legs while it was swimming with the agility that has been imputed to it.

The weight of Diplodocus and of Brontosaurus furnishes a strong argument against their having had a

${ }^{13}$ Mem. Amer. Mus. Nat. Hist., I, p. 210.

${ }^{14}$ Mem. Carnegie Mus., II, p. 73, Fig. 1.

${ }^{15}$ Op. cit., $\mathrm{Pl}$. VI. 
mammal-like carriage. There will be little dissent from the view that these animals inhabited a country in which marshy lands abounded and that they passed the most of their time in the vicinity of bodies of water. As to weight, Marsh estimated that that of Brontosaurus was more than twenty tons. Each footprint was thought to be about a square yard in extent. The pressure was therefore about 1,100 pounds on each square foot of the ground. What progress could such enormous animals have made through morasses and along mud-depositing rivers, in case they carried themselves as they are represented in the restorations? Without doubt, they would soon have become inextricably mired and would have perished miserably.

Osborn ${ }^{16}$ has suggested that Camarasaurus, another sauropod was accustomed to wading about in rivers where the bottoms were sandy and firm. The habits of Diplodocus could have differed little from those of Camarasaurus. It is difficult to understand why an animal whose immediate ancestors must have walked about in a crocodile-like manner, an animal that was stupid and probably slow of movement, an animal which could by means of its long neck reach up from the bottom many feet to the surface and from the surface many feet to the bottom - why such a reptile should need to develop the ability to walk along river bottoms like a mammal. Furthermore, it seems somewhat overgenerous to impute to a reptile so many and so diverse activities as swimming with great facility, walking on river bottoms and on the land with mammal-like gait, and on occasion erecting itself on its hinder legs after the manner of a bird, in order to crop the foliage from the tops of high trees, when this reptile was sixty feet long, weighed many tons, had a brain little larger than one's two thumbs placed side by side, and was provided with a feeble dental apparatus with which to gather food wherewith to support its huge body, and that food of a sort that yielded little energy in proportion to its bulk.

${ }^{16}$ Bull. Amer. Mris. Nat. Hist., X, p. 220. 
The writer's conception of Diplodocus is that it was eminently amphibious, that it could swim with considerable ease, and that it could creep about on land, with perhaps laborious effort. When feeding it must have swam or crept lazily about, gathering in floating plants and such as were attached loosely to the bottom. If any plants that were relished grew at some depth they could be reached by the long neck; or, if there was foliage twenty feet above the water it could be as easily gathered in. That a Diplodocus ever stood on its hind lgs is hardly more probable than that crocodiles may perform the same feat.

The large size of Diplodocus does not preclude the possibility that it could creep about on the land. Crocodylus robustus, of Madagascar, is said to attain a length of 10 meters, and yet it doubtless is able to walk as other crocodiles walk. The limb bones of Diplodocus and of Brontosaurus are proportionally as large as those of crocodiles.

It seems to the writer that our museums which are engaged in making mounts and restorations of the great Sauropoda have missed an opportunity to construct some striking presentations of these reptiles that would be truer to nature. The body placed in a crocodile-like attitude would be little, if any, less, imposing than when erect; while the long neck, as flexible as that of an ostrich, might be placed in a variety of graceful positions. 